\title{
Research on Francis Turbine Modeling for Large Disturbance Hydropower Station Transient Process Simulation
}

\author{
Guangtao Zhang, ${ }^{1}$ Yuanchu Cheng, ${ }^{1}$ and $\mathrm{Na}^{\mathrm{Lu}}{ }^{2}$ \\ ${ }^{1}$ School of Power and Mechanical Engineering, Wuhan University, Wuhan 430072, China \\ ${ }^{2}$ College of Water Resources and Architectural Engineering, Northwest A\&F University, Yangling 712100, China \\ Correspondence should be addressed to Yuanchu Cheng; xhzh2013@whu.edu.cn
}

Received 8 July 2015; Accepted 3 November 2015

Academic Editor: Renata Archetti

Copyright (c) 2015 Guangtao Zhang et al. This is an open access article distributed under the Creative Commons Attribution License, which permits unrestricted use, distribution, and reproduction in any medium, provided the original work is properly cited.

In the field of hydropower station transient process simulation (HSTPS), characteristic graph-based iterative hydroturbine model (CGIHM) has been widely used when large disturbance hydroturbine modeling is involved. However, by this model, iteration should be used to calculate speed and pressure, and slow convergence or no convergence problems may be encountered for some reasons like special characteristic graph profile, inappropriate iterative algorithm, or inappropriate interpolation algorithm, and so forth. Also, other conventional large disturbance hydroturbine models are of some disadvantages and difficult to be used widely in HSTPS. Therefore, to obtain an accurate simulation result, a simple method for hydroturbine modeling is proposed. By this method, both the initial operating point and the transfer coefficients of linear hydroturbine model keep changing during simulation. Hence, it can reflect the nonlinearity of the hydroturbine and be used for Francis turbine simulation under large disturbance condition. To validate the proposed method, both large disturbance and small disturbance simulations of a single hydrounit supplying a resistive, isolated load were conducted. It was shown that the simulation result is consistent with that of field test. Consequently, the proposed method is an attractive option for HSTPS involving Francis turbine modeling under large disturbance condition.

\section{Introduction}

As energy demand grows and technology advances, more and more hydropower stations are being built or planned to be built. In addition, many existing hydropower stations need to be overhauled or improved to meet new requirements after operating for some time. In this case, to ensure the operating safety of hydropower station with newly designed hydraulic system and wicket gate closing and opening law, detailed hydropower station transient process simulation (HSTPS), which can offer predictions of maximum speed, maximum pressure, and minimum pressure [1], should be conducted before the construction or improvement of hydropower station. In the past, hydropower station transients have caused many catastrophes like equipment damage and casualties [ 1 , 2]. Therefore, the research on HSTPS is of great importance.

Generally, the key to obtain an accurate result of HSTPS lies in the model. Hydropower station transient process model mainly consists of four submodels, that is, (1) pressure conduit system model, (2) large disturbance hydroturbine model (LDHM), (3) governor and servomotor model, and (4) generator and load model. Among these submodels, pressure conduit system model $[1,2]$, governor and servomotor model [1], and generator and load model $[1,3]$ have been well studied. However, because of limited knowledge of the complicated dynamic characteristic of hydroturbine and the flowing process of water through hydroturbine, the LDHM is still being developed. In general, there are mainly two types of LDHM widely used for HSTPS. One is characteristic graph-based iterative hydroturbine model (CGIHM), for which the transient turbine pressure head and rotational speed are calculated by iterations on the steadystate hydroturbine characteristic graph $[1,2]$. This type of model can provide relatively accurate results in most cases and is convenient to use. Hence it has been used widely for HSTPS, especially when reaction hydroturbine like Francis or Kaplan turbine is applied [2] (for simplicity, only Francis turbine is discussed in this paper hereon). However, because 
of the using of iterative algorithm, slow convergence or no convergence problems may be encountered due to some reasons like special characteristic graph profile, inappropriate iterative algorithm, or inappropriate interpolation algorithm $[4,5]$, and so forth. Another popular type of LDHM is valve-assumption hydroturbine model (VHM), for which the hydroturbine is assumed as a valve and the turbine dischargepressure head model is represented by a valve equation [6-8]. This model is simple, analytical, and appropriate to simulate the impulse turbine; hence it has been used widely in power system simulation $[7,8]$. However, the valve-assumption of VHM may not be valid for Francis turbine [2], because the turbine discharge is not only the function of turbine head and gate opening, but also the function of the rotational speed which changes dramatically for most of the HSTPSs.

Besides the above two popular types of LDHM, some other types of LDHM have also been investigated by researchers. The one described in $[9,10]$ was realized by an internal characteristic analysis method. This model has been used in some engineering cases, and good consistency between simulation results and field test results was claimed. But this method needs detailed turbine parameters such as flow areas and outflow angle of turbine runner [9], which are difficult to acquire. As another method of representing the turbine characteristic graph, neural network hydroturbine model also needs iterations in its simulation process and suffers from nonconvergence problem [11]. In [12], a threedimensional flow model was used to represent the hydroturbine characteristics and it was indicated that this model could provide rational results without the need for hydroturbine characteristic graph. However, to build the three-dimensional model of hydroturbine, very detailed turbine parameters such as the geometric parameters of turbine water passage are needed, whereas these parameters are quite difficult to acquire. As a result, to the knowledge of the authors, there seems to be no appropriate LDHM for HSTPS when CGIHM cannot offer convergence results. So this paper focuses on this problem and proposed a simple and accurate type of LDHM for HSTPS.

The paper is arranged in the following sequence, after introduction of the problems of existing LDHMs for HSTPS in Section 1, the advantage and disadvantage of an existing turbine modeling method are discussed in Section 2. Based on the discussion in Section 2, a new Francis modeling method under large disturbance condition for HSTPS is proposed in Section 3. In Section 4, a model of a single Francis hydrounit supplying a resistive, isolated load is built, and then the effectiveness of the proposed method is verified by comparing the simulation result with the field test result under several typical disturbance conditions. Finally, conclusions are given in the last section.

\section{Variable Transfer Coefficients Hydroturbine Model}

It is worth noting that a variable transfer coefficients hydroturbine model (VTCHM) was adopted in [13] to build a hydroturbine regulating system under MATLAB/Simulink

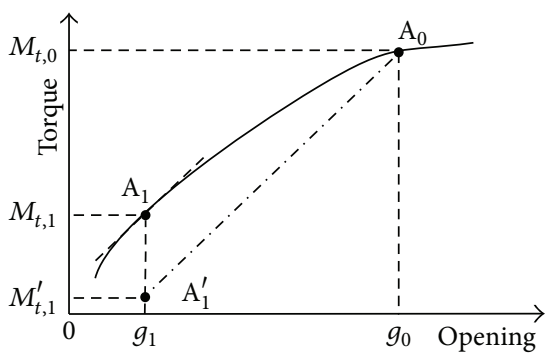

FIgURE 1: A schematic diagram to show the problem when VTCHM is used for large disturbance simulation.

environment. This model is a linear turbine model expressed as

$$
\begin{gathered}
\Delta m_{t}=e_{m g} \Delta g+e_{m h} \Delta h+e_{m x} \Delta x, \\
\Delta q=e_{q g} \Delta g+e_{q h} \Delta h+e_{q x} \Delta x,
\end{gathered}
$$

where the 6 transfer coefficients are updated according to the gate opening $g$ and unit speed $n_{11}$ by look-up table and interpolation method.

In (1), $\Delta m_{t}, \Delta q, \Delta g, \Delta h$, and $\Delta x$ are deviations of turbine torque $m_{t}$ per unit (hereinafter referred to as p.u.) based on rated turbine torque, discharge $q$ p.u. based on rated discharge, gate opening $g$ p.u. based on maximum opening, operating head $h$ p.u. based on rated head, and speed $x$ p.u. based on rated speed, respectively. They are expressed as $\Delta m_{t}=m_{t, k}-m_{t, 0}, \Delta q=q_{k}-q_{0}, \Delta g=g_{k}-g_{0}, \Delta h=h_{k}-h_{0}$, and $\Delta x=x_{k}-x_{0}$, where $k$ denotes the current simulation step, $k=$ $1,2, \ldots$, end of simulation, and 0 denotes the initial value before the first simulation step. The 6 transfer coefficients can be written as $e_{m g}=\partial m_{t} / \partial g, e_{m x}=\partial m_{t} / \partial x, e_{m h}=\partial m_{t} / \partial h$, $e_{q g}=\partial q / \partial g, e_{q h}=\partial q / \partial h$, and $e_{q x}=\partial q / \partial x$. These coefficients change with $g_{k}$ and $n_{11, k}$ in the simulation process. The unit speed [1] can be expressed as $n_{11, k}=x_{k} / \sqrt{h_{k}}$.

It can be seen from (1) that VTCHM is a type of SDHM with the transfer coefficients updating according to current $g$ and $n_{11}$. It is because of the changing of the transfer coefficients in the simulation process that the result is relatively more accurate than the one obtained when the transfer coefficients are fixed. However, this model should not be used for large disturbance hydroturbine simulation, because it is still linearized around the initial operating point. This means that, no matter where the real operating point is, $m_{t}$ and $q$ are calculated from that fixed operating point in the simulation process. Consequently, error would be increased when the simulation operating point gets far away from the initial operating point. To demonstrate this reason clearly, the schematic diagram of a torque-opening characteristic is shown in Figure 1. As can be seen from Figure 1, when the operating point changes from initial point $\mathrm{A}_{0}\left(g_{0}, M_{t, 0}\right)$ to a new operating point $\mathrm{A}_{1}\left(g_{1}, M_{t, 1}\right)$, if the transfer coefficients in $\mathrm{A}_{1}$ and the initial operating point $\mathrm{A}_{0}$ are used to calculate the torque, a result $M_{t, 1}^{\prime}$ corresponding to the point $A_{1}^{\prime}$ will be obtained. Apparently, there is error between the obtained torque $M_{t, 1}^{\prime}$ and the actual torque $M_{t, 1}$. And the error may become larger when the current operating 
point gets further away from the initial operating point or the nonlinear characteristic of the turbine becomes stronger.

From the above analysis, it can be known that the reason for the producing of the error is that the initial operating point keeps the same during the process of simulation. This makes the new operating point become so far away from the current operating point during large disturbance simulation that the linear approximation method may become no longer valid. In order to overcome this disadvantage of VTCHM, a variable initial operating point and transfer coefficients method is proposed in this paper to build Francis turbine model for HSTPS under large disturbance condition (for convenience, the model is expressed as VIOP-TCHM in the following part of this paper). By this method, both the initial operating point and transfer coefficients of Francis turbine model keep changing during the process of large disturbance simulation, so that the initial operating point can be close to the current operating point. Then, by contrast with VTCHM, more accurate result can be obtained.

\section{Variable Initial Operating Point and Transfer Coefficients Method}

As mentioned above, when the variable values of initial operating point are specified as constants in the process of simulation, the error may become larger as the current operating point gets further away from the initial operating point or the nonlinear characteristic of the turbine gets stronger. In order to overcome this defect, a modeling method with both the initial operating point and the transfer coefficients updating in the process of simulation is proposed in this paper.

To give the derivation of this method, two assumptions are given first as follows.

Assumption 1. For general engineering, the variable values in transient process of hydroturbine are approximately equal to those in steady state.

Assumption 2. Under small disturbance condition, the hydroturbine model can be linearized around the initial steady-state operating point.

Here, the first assumption is assumed to be valid for general engineering application $[1,2,14]$, and the second one has been widely accepted and used in the area of turbine modeling $[8,15,16]$.

3.1. Formula Derivation. According to Assumption 1, the variable values of initial operating point at the end of each simulation step (the time step $\Delta t$ in numerical integration methods [8]) can be calculated by those at the end of previous step plus an increment. It can be expressed as

$$
\begin{gathered}
m_{t, k}=m_{t, k-1}+\Delta m_{t, k-1}^{\prime}, \\
q_{k}=q_{k-1}+\Delta q_{k-1}^{\prime}, \\
g_{k}=g_{k-1}+\Delta g_{k-1}^{\prime},
\end{gathered}
$$

$$
\begin{aligned}
& h_{k}=h_{k-1}+\Delta h_{k-1}^{\prime}, \\
& x_{k}=x_{k-1}+\Delta x_{k-1}^{\prime},
\end{aligned}
$$

where $\Delta m_{t, k-1}^{\prime}, \Delta q_{k-1}^{\prime}, \Delta g_{k-1}^{\prime}, \Delta h_{k-1}^{\prime}$, and $\Delta x_{k-1}^{\prime}$ are deviations of $m_{t}, q, g, h$, and $x$, respectively, between current and previous simulation step. When the system gets into steady state, all these deviations equal zero.

Note that the meanings of the deviations shown here are different from those in (1). In (1), the deviations are calculated from the initial values while, in (2) to (6), the deviations are calculated from the previous step results. To distinguish them clearly, superscript apostrophes are used in (2) to (6).

The water hammer head [17] is presented as

$$
\Delta h_{k}^{\prime \prime}=h_{k}-h_{0}
$$

where $h_{k}$ can be calculated by (5).

And the transfer function of water hammer equation can be written for VIOP-TCHM as

$$
G_{h}(s)=\frac{\Delta h_{k}^{\prime \prime}(s)}{q_{k}(s)},
$$

where the expression of $G_{h}(s)$ differs depending on research purpose and water conduit length $[1,7]$. The water hammer model of pressure conduit can be generally divided into inelastic water hammer model and elastic water hammer model, among which the inelastic water hammer model is much simpler and used more widely. According to [7, 13, 17], the inelastic water hammer model applies to short or medium length pressure conduit. Considering that this paper focuses on the hydroturbine modeling, the inelastic water hammer model is used for analysis. The transfer function of inelastic water hammer model is shown as

$$
G_{h}(s)=\frac{\Delta h^{\prime \prime}(s)}{q(s)}=-T_{w} s,
$$

where $T_{w}[1,18]$ is water inertia time constant in s and can be calculated by

$$
T_{w}=\frac{L Q_{r}}{a_{g} A H_{r}},
$$

where $L$ is the length of pressure conduit in $m ; Q_{r}$ is rated water flow in $\mathrm{m}^{3} / \mathrm{s} ; a_{g}$ is local acceleration due to gravity in $\mathrm{m} / \mathrm{s}^{2} ; A$ is the cross section area of conduit in $\mathrm{m}^{2}$; and $H_{r}$ is rated hydroturbine operating head in $\mathrm{m}$.

3.2. Simulation Block Diagram. According to Assumption 2, VIOP-TCHM can be linearized around the current initial operating point as

$$
\begin{gathered}
\Delta m_{t}^{\prime}=e_{m g} \Delta g^{\prime}+e_{m h} \Delta h^{\prime}+e_{m x} \Delta x^{\prime}, \\
\Delta q^{\prime}=e_{q g} \Delta g^{\prime}+e_{q h} \Delta h^{\prime}+e_{q x} \Delta x^{\prime} .
\end{gathered}
$$

According to (2)-(6) and (11)-(12), a block diagram of VIOP-TCHM can be obtained as shown in Figure 2, where 


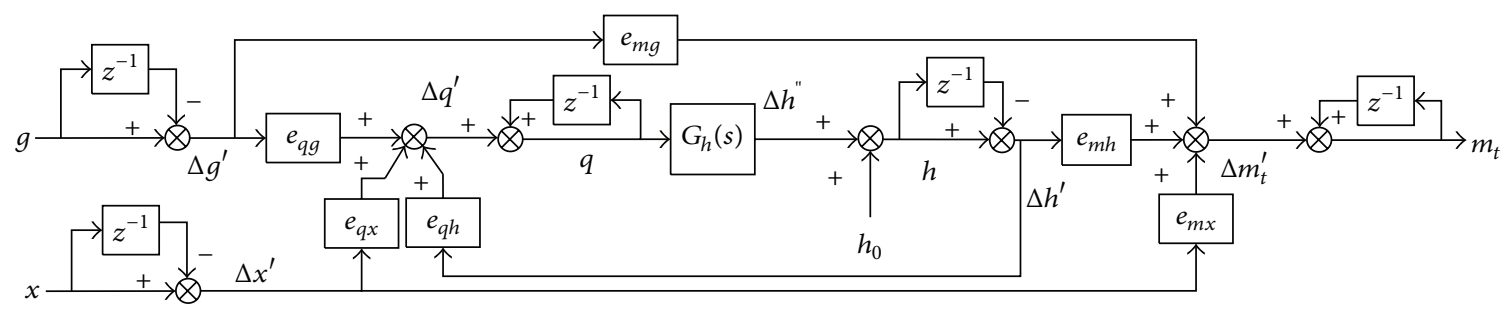

Figure 2: Block diagram of VIOP-TCHM.

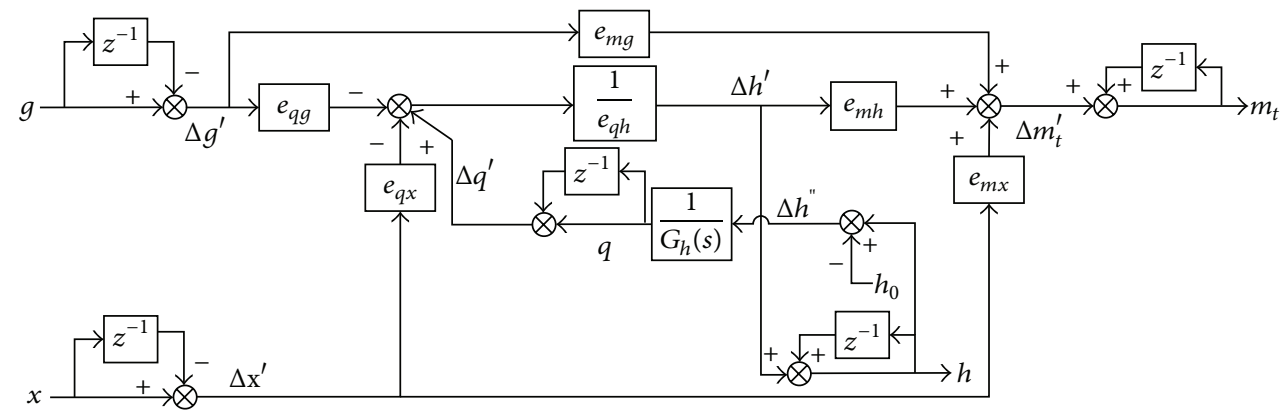

FIGURE 3: Improved block diagram of VIOP-TCHM.

$z^{-1}$ represents a transport delay module. However, when this block diagram was used for large disturbance simulation, divergence phenomenon often occurred. The analysis reveals that the reason lies in the water hammer equation (9). When $\Delta h^{\prime \prime}(s)$ is calculated by (9), there is a numerical differential link which will exemplify the numerical error [19] and lead to an unstable calculation result.

To avoid the numerical differential link, an improved block diagram of VIOP-TCHM is obtained by optimizing the calculation sequence. The details are as follows.

Firstly, for each simulation step, $q_{k}$ is calculated by integrating the water hammer head $\Delta h_{k-1}^{\prime \prime}$ by

$$
q_{k}=-\frac{1}{T_{w} s} \Delta h_{k-1}^{\prime \prime} .
$$

Then, calculate $\Delta q_{k}^{\prime}$ by

$$
\Delta q_{k}^{\prime}=q_{k}-q_{k-1}
$$

After that, calculate $\Delta h^{\prime}$ by

$$
\Delta h_{k}^{\prime}=\frac{\Delta q_{k}^{\prime}-e_{q g} \Delta g_{k}^{\prime}-e_{q x} \Delta x_{k}^{\prime}}{e_{q h}}
$$

which is a transformation of (12).

At last, calculate $h$ and $m_{t}$ by (5) and (2), respectively.

Then, according to (2), (4)-(7), (11), and (13)-(15), the improved block diagram of VIOP-TCHM is obtained as shown in Figure 3. Moreover, the flowchart for the entire computational procedure of VIOP-TCHM is shown in Figure 4.

By the improved block diagram, the numerical differential link is changed into integration link. Therefore, the error exemplifying effect can be avoided. Simulations, even under quite serious disturbance conditions, have validated that stable results can be obtained by the block diagram shown in Figure 3.

With regard to the calculation of $e_{q x}, e_{q g}, e_{q h}, e_{m x}, e_{m g}$, and $e_{m h}$, the method in [13] was used in this paper.

\section{Case Study}

To verify the effectiveness of the proposed modeling method, a digital model of an actual hydroturbine unit in China was built, and comparisons between simulations and actual processes were conducted.

4.1. Introduction to Hydrounit for Case Study. The unit simulated in this paper is a vertical shaft Francis turbine unit of an actual hydropower station at the dam toe. The hydraulic system of the unit consists of a pressure penstock with length of $175 \mathrm{~m}$, a hydroturbine, and a tail water tunnel. There is no surge tank in upstream or downstream conduit. In addition, the pressure conduit has a quite short length of $277.4 \mathrm{~m}$. Therefore, the inelastic water hammer model is employed for simulation. The basic parameters of the unit are provided in Table 1.

In Table $1, P_{r}$ is rated power output of the hydroturbine; $D_{1}$ is runner diameter of the hydroturbine.

4.2. Simulation Model. To highlight the focus of this paper, a single unit supplying a resistive isolated load is considered. In addition, since the main process concerned in this paper is the rotational speed-pressure head transient process, the electromagnetic process is ignored by using a first-order generator 


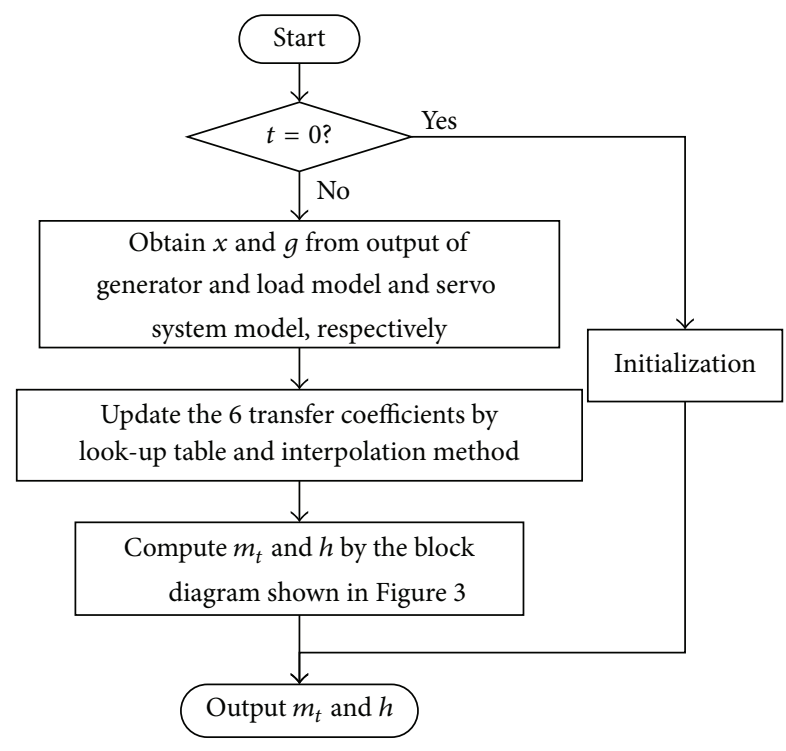

FIGURE 4: Flowchart for the entire computational procedure of VIOP-TCHM.

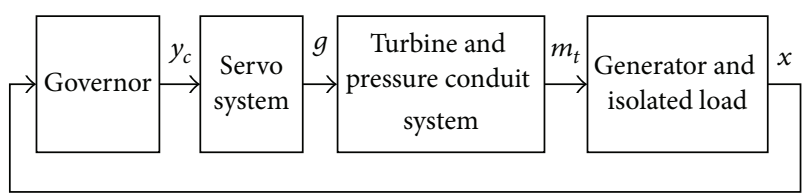

FIGURE 5: System model for case study.

TABLE 1: Basic parameters of the unit.

\begin{tabular}{lc}
\hline Parameter & Value \\
\hline$H_{r}(\mathrm{~m})$ & 111 \\
$P_{r}(\mathrm{MW})$ & 600 \\
$n_{r}(\mathrm{r} / \mathrm{min})$ & 93.75 \\
$D_{1}(\mathrm{~m})$ & 7.8 \\
$Q_{r}\left(\mathrm{~m}^{3} / \mathrm{s}\right)$ & 597.95 \\
\hline
\end{tabular}

model, and the electric network and load characteristic are simplified as a load torque represented by a step module.

4.2.1. System Model. As can be seen in Figure 5, the system model consists of governor, servo system, turbine and pressure conduit system, and generator and isolated load. By this model, the rotational speed $x$, feedback from the generator and isolated load model, is compared with the reference value firstly. Then, the comparison result is used to calculate a gate opening control signal $y_{c}$ by the governor model. After that, $y_{c}$ is processed by the servo system model to be the servomotor opening output, which equals turbine gate opening $g$ when the nonlinearity between servomotor opening and gate opening is ignored. Receiving the new gate opening value $g$, the turbine and pressure conduit system model will work to update the flow $q$, water head $h$, and

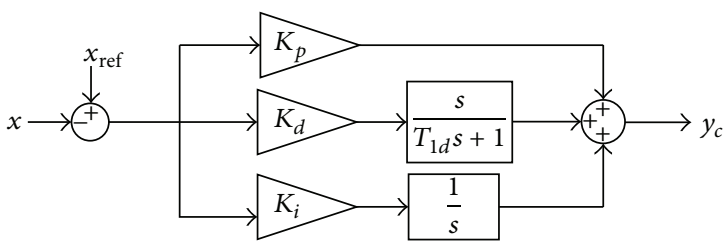

FIGURE 6: Governor model for case study.

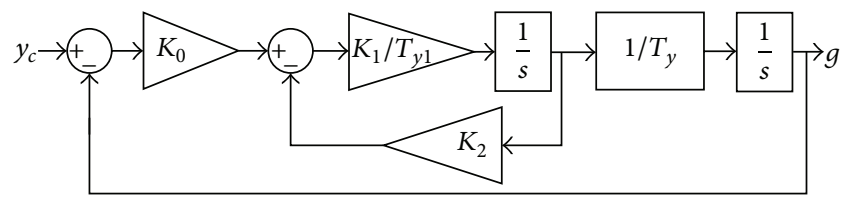

FIgURE 7: Servo system model for case study.

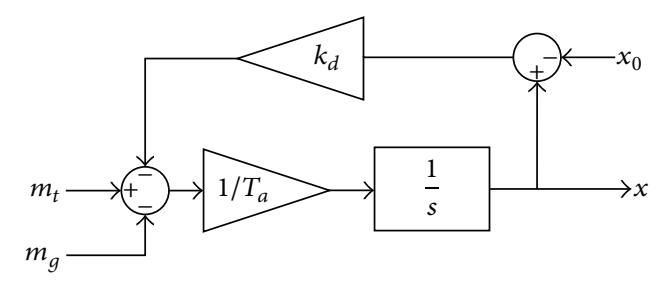

FIgURE 8: Generator and isolated load model for case study.

mechanical torque $m_{t}$ to new states. Then, with the new $m_{t}$, speed $x$ will be updated after some response time by the generator and isolated load model. Note that when written in per unit, the rotational speed is equal to the frequency.

4.2.2. Governor Model. The block diagram of governor model shown in Figure 6 is a typical PID controller. In this diagram, $x$ is the same as that in Figure 5; $x_{\text {ref }}$ is speed reference; $K_{p}$, $K_{i}$, and $K_{d}$ are proportional, integral, and differential gains, respectively; $T_{1 d}$ is differential time constant; and $y_{c}$ is the control output of the governor model.

4.2.3. Servo System Model. Figure 7 shows the block diagram of the servo system model. Here, $K_{0}$ is a forward gain representing the electrohydraulic converter; $K_{1}$ and $K_{2}$ are the forward and feedback gains of the ancillary servomotor, respectively; and $T_{y 1}$ and $T_{y}$ are the response time constants of ancillary servomotor and main servomotor, respectively.

4.2.4. Turbine and Pressure Conduit System Model. The proposed VIOP-TCHM shown in Figure 3 is used as the turbine and pressure conduit system model. Its 6 transfer coefficient tables are calculated by the method proposed in [13].

4.2.5. Generator and Isolated Load Model. The block diagram of generator and isolated load model is shown in Figure 8, where $k_{d}$ is damping coefficient; $x_{0}$ is initial steady-state rotational speed; and $m_{g}$ is generator load torque which is set by a step function module. 


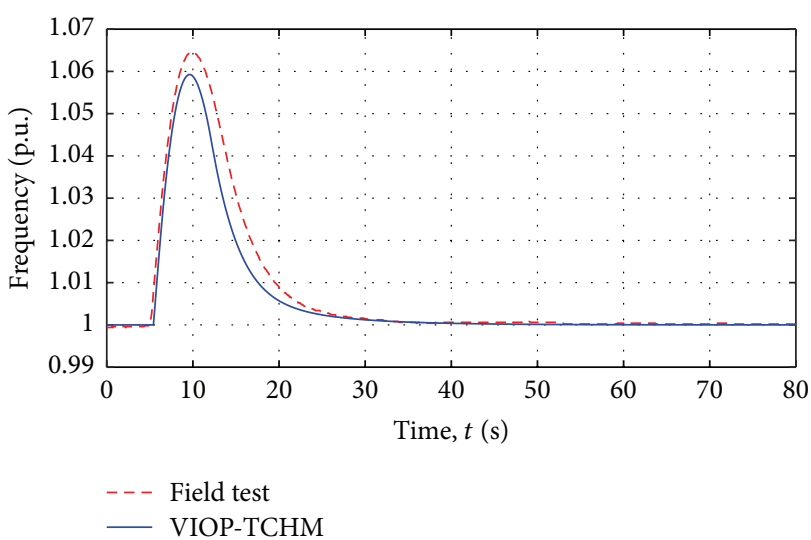

(a) Frequency response

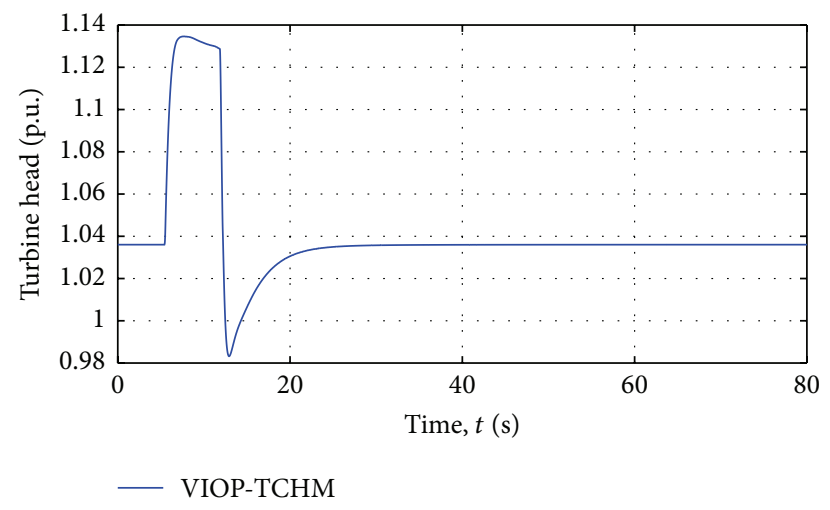

(b) Turbine head response

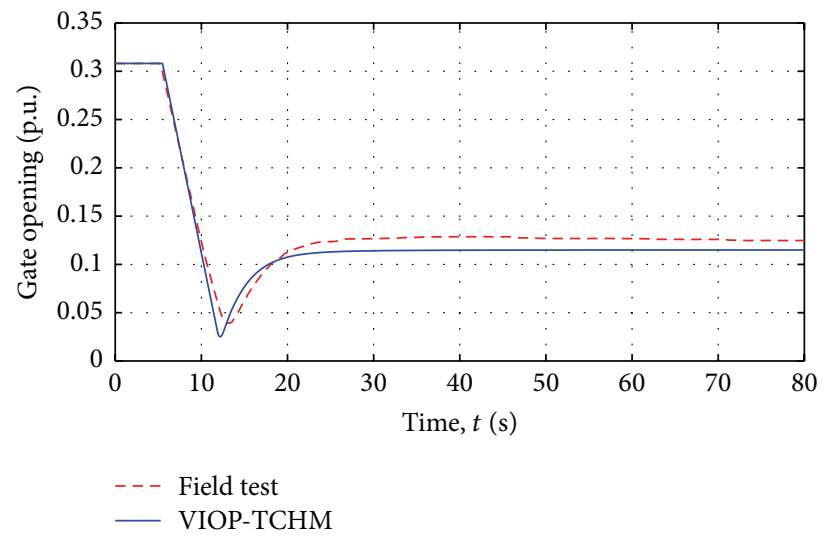

(c) Gate opening response

FIGURE 9: Response to 25\% rated load rejection.

4.3. Results and Analysis. To validate the effectiveness of the proposed VIOP-TCHM, simulations were carried out. Considering the concern of this paper is the modeling method of hydroturbine for HSTPS under large disturbance condition, and load rejections may be those of the most serious large disturbances the hydrounit can encounter. Hence some load rejection simulations were conducted.

The values of parameters for simulation are listed in Table 2 , and the simulation step $\Delta t$ was set to $0.015 \mathrm{~s}$. The results of $25 \%, 50 \%$, and $75 \%$ rated load rejection simulations are shown in Figures 9, 10, and 11, respectively. Their corresponding initial parameter values are listed in Table 3. In addition, the results of no-load frequency disturbance simulation with the frequency reference stepping from 1.0 p.u. to 1.02 p.u. then back to 1.0 p.u. are shown in Figure 12. The initial variable values of no-load frequency disturbance simulation are listed in Table 4.

4.3.1. Large Disturbance Simulation. As can be seen from Figure 9, at $t=4.5$ th second, $25 \%$ rated load rejection was imposed through changing the load torque from initial value to 0 . Because the turbine torque $m_{t}$ was controlled by governor, when the load torque $m_{g}$ stepped to zero, the turbine torque cannot change to zero immediately but kept nearly the same until governor started to regulate.
TABLE 2: Parameters for simulation.

\begin{tabular}{lc}
\hline Parameter & Value \\
\hline$T_{a}(\mathrm{~s})$ & 9.82 \\
$T_{w}(\mathrm{~s})$ & 1.887 \\
$K_{p}$ & 4.5 \\
$K_{i}$ & 0.4 \\
$K_{d}$ & 3.5 \\
$T_{1 d}(\mathrm{~s})$ & 0.15 \\
$K_{0}$ & 5.0 \\
$K_{1}$ & 1.2 \\
$K_{2}$ & 0.8 \\
$T_{y 1}(\mathrm{~s})$ & 0.1 \\
$T_{y}(\mathrm{~s})$ & 3.15 \\
$k_{d}$ & 0.0 \\
\hline
\end{tabular}

Consequently, a net accelerating torque $m_{a}=m_{t}$ emerged, and then the unit began to speed up. When the speed was high enough, as shown in Figure 9(c), at $t=4.86$ th second, the governor worked to decrease the gate opening to reduce the turbine torque. However, the speed still kept increasing until the turbine torque became smaller than the damping torque which is composed of water friction, air friction, and 


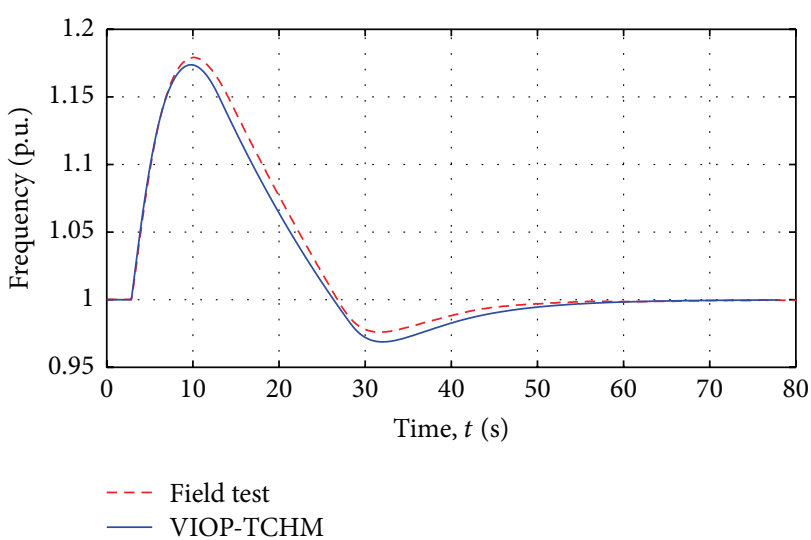

(a) Frequency response

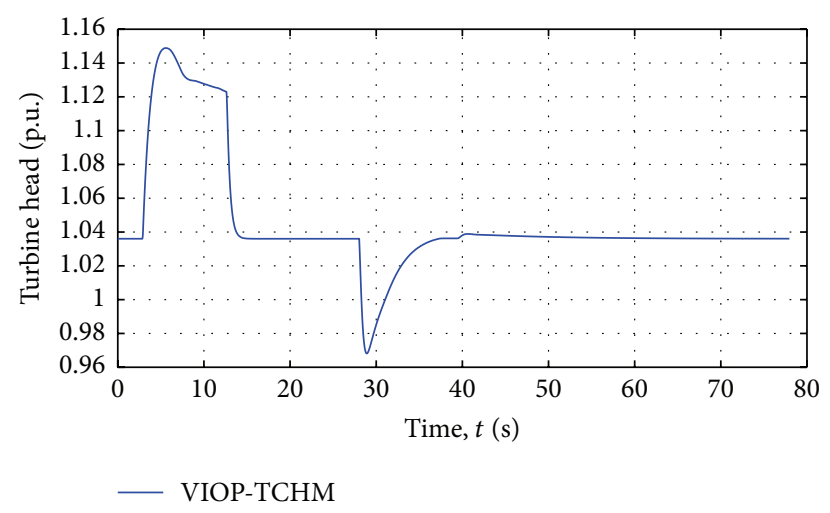

(b) Turbine head response

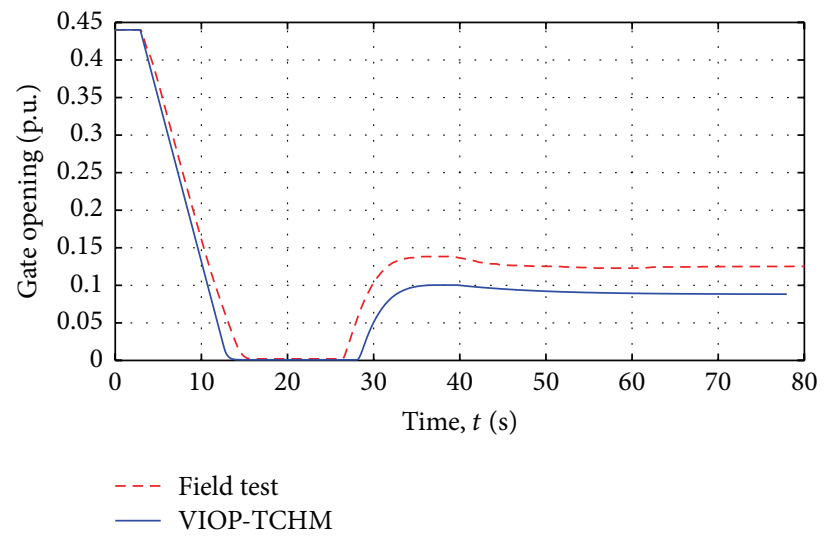

(c) Gate opening response

FIgURE 10: Response to 50\% rated load rejection.

TABLE 3: Initial values for load rejection simulations.

\begin{tabular}{lccc}
\hline Variable & $\begin{array}{c}\text { 25\% rated } \\
\text { load rejection }\end{array}$ & $\begin{array}{c}50 \% \text { rated } \\
\text { load rejection }\end{array}$ & $\begin{array}{c}75 \% \text { rated } \\
\text { load rejection }\end{array}$ \\
\hline$h_{0}$ (p.u.) & 1.036 & 1.036 & 1.036 \\
$q_{0}$ (p.u.) & 0.3137 & 0.4945 & 0.6811 \\
$g_{0}$ (p.u.) & 0.3081 & 0.4401 & 0.5929 \\
$m_{t, 0}$ (p.u.) & 0.2488 & 0.4892 & 0.7458 \\
\hline
\end{tabular}

TABLE 4: Initial values for no-load frequency disturbance simulation.

\begin{tabular}{lc}
\hline Variable & Value \\
\hline$h_{0}$ (p.u.) & 1.036 \\
$q_{0}$ (p.u.) & 0.1211 \\
$g_{0}$ (p.u.) & 0.1259 \\
$m_{t, 0}$ (p.u.) & 0.0 \\
\hline
\end{tabular}

mechanical friction, and so forth. When gate opening started to decrease, turbine head increased sharply. As shown in Figure 9(b), the maximum turbine head 1.135 p.u. emerged at $t=7.26$ th second, that is, about 2.4 seconds after the moment when the gate opening started to decrease. At $t=9.61 \mathrm{st}$ second, the frequency increased to the maximum value; meanwhile the gate opening reached around the no-load opening. Thereafter, because the frequency was still much larger than reference value, the governor kept decreasing the gate opening to reduce the speed. At $t=12.07$ th second, the governor started to increase the gate opening to avoid overregulation of the frequency, and turbine head reached the minimum value 0.9832 p.u. after about 0.88 seconds since the gate opening started to increase. When, at $t=25$ th second, the frequency came back to the frequency deadband of governor and gate opening stabilized around the noload opening, turbine head restored to the value before the disturbance and the unit got into a new steady state.

From the curves shown in Figure 9, it can be observed that the contours of the VIOP-TCHM result and the field test result are consistent. In addition, the rising time period, descending process time period, and peak value on the frequency curves of VIOP-TCHM are quite close to those of the field test. This indicates that, through using the VIOPTCHM as the turbine model for HSTPS, a quite accurate result can be obtained. Note that the turbine head curve was not recorded in the field test; hence the turbine head comparison between simulation result and test result was not conducted. However, the simulation process of turbine head is consistent with the typical load rejection process. 


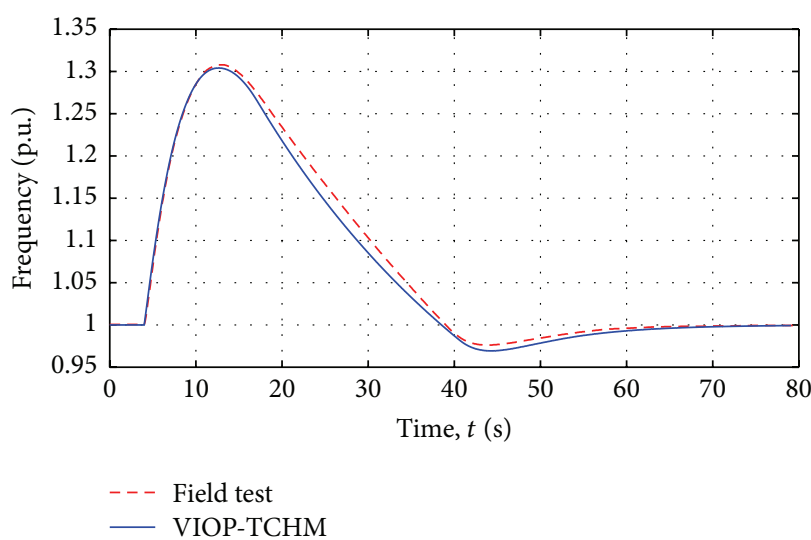

(a) Frequency response

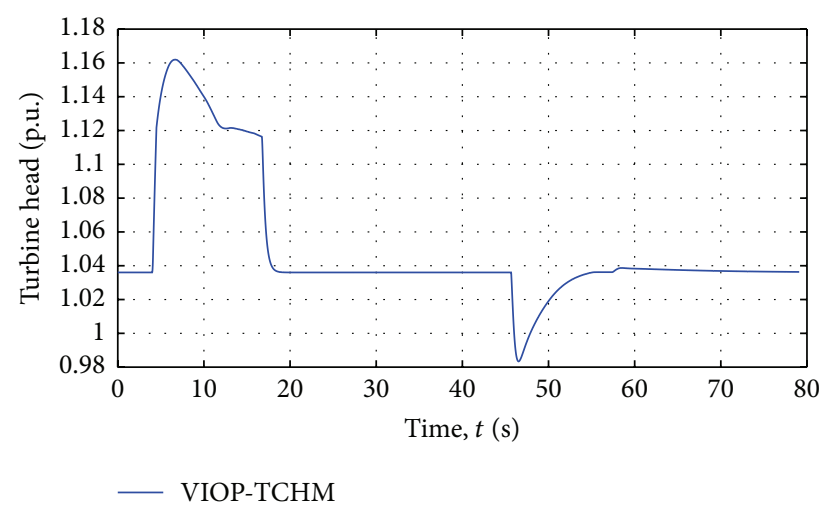

(b) Turbine head response

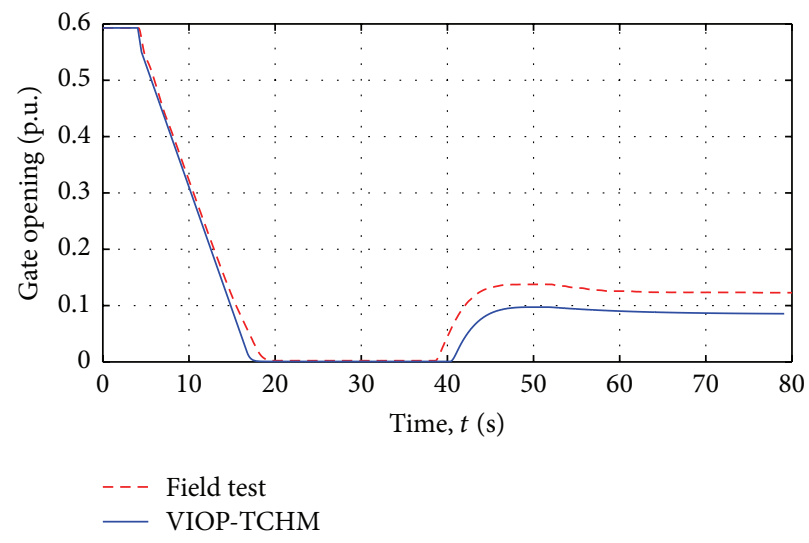

(c) Gate opening response

FIGURE 11: Response to $75 \%$ rated load rejection.

From Figures 10 and 11, it can be seen that the simulation curves under $50 \%$ and $75 \%$ rated load rejection conditions look similar to those under $25 \%$ rated load rejection condition, except that the peak value of frequency becomes larger and a valley emerged on the frequency curve as the initial load increasing, which may have something to do with the parameter settings of the governor.

Figures 10 and 11 also show that the simulation result is quite close to the field test result which indicates that the VIOP-TCHM is quite accurate.

4.3.2. Small Disturbance Simulation. To verify the performance of VIOP-TCHM further, small disturbance simulations were also conducted. The result is shown in Figure 12. In the beginning, the unit was operating under steadystate no-load operating condition. Then, a step disturbance was imposed on the unit suddenly at $t=1$.81st second by making the value of governor reference frequency change from 1.0 p.u. to 1.02 p.u. At $t=2.02 \mathrm{nd}$ second, the gate opening started to respond and increase sharply, and, almost at the same time, turbine head started to decrease. At $t=$ 3.08th second, turbine head reached the minimum value 0.9196 p.u. Likewise, at $t=63.17$ th second, there was a step change of reference frequency from 1.02 p.u. to 1.0 p.u. This led to the decrease of the gate opening at $t=63.25$ th second and the increase of turbine head. In this process, it can be seen that the curves obtained by taking VIOP-TCHM as the hydroturbine model and those by field test have similar contours, which validates the accuracy of the VIOP-TCHM under small disturbance condition.

\section{Conclusion}

Considering that CGIHM, the most widely used large disturbance hydroturbine model in HSTPS, may fail to give results for Francis turbine simulation in some cases, a simple variable initial operating point and transfer coefficients method is proposed in this paper for Francis turbine modeling. By this method, VIOP-TCHM is constructed. To validate the accuracy of VIOP-TCHM, both of large disturbance and small disturbance numerical simulations were carried out. It was shown that the result obtained by VIOP-TCHM was consistent with that by field test. Therefore, with characteristics of simple structure, definite physical meaning, and accurate calculation result, VIOP-TCHM can be effectively used in the HSTPS involving Francis turbine modeling under large disturbance condition. 


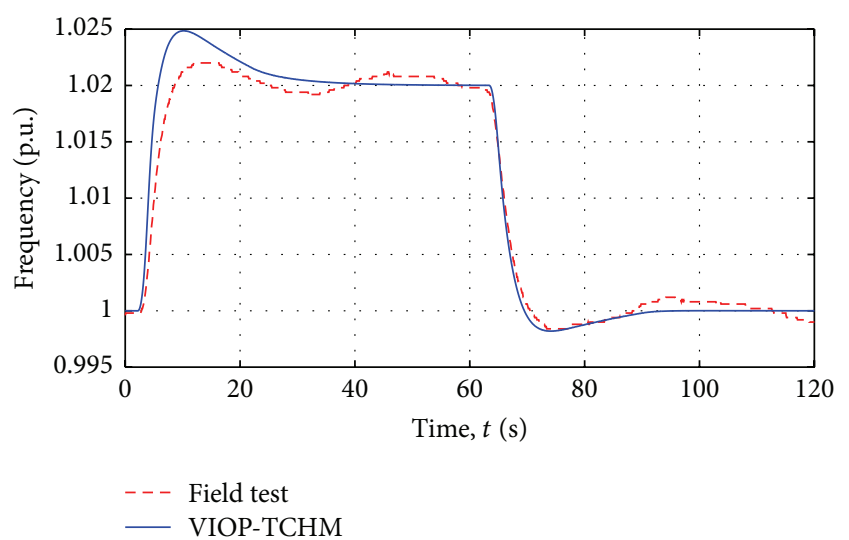

(a) Frequency response

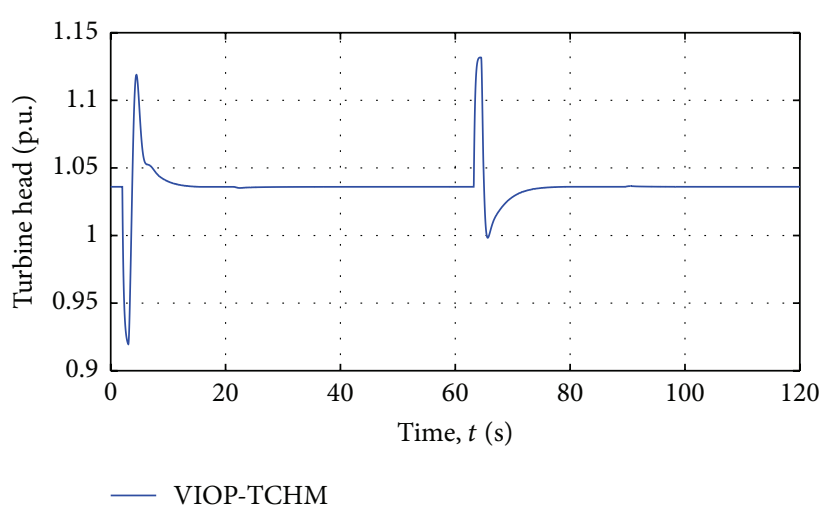

(b) Turbine head response

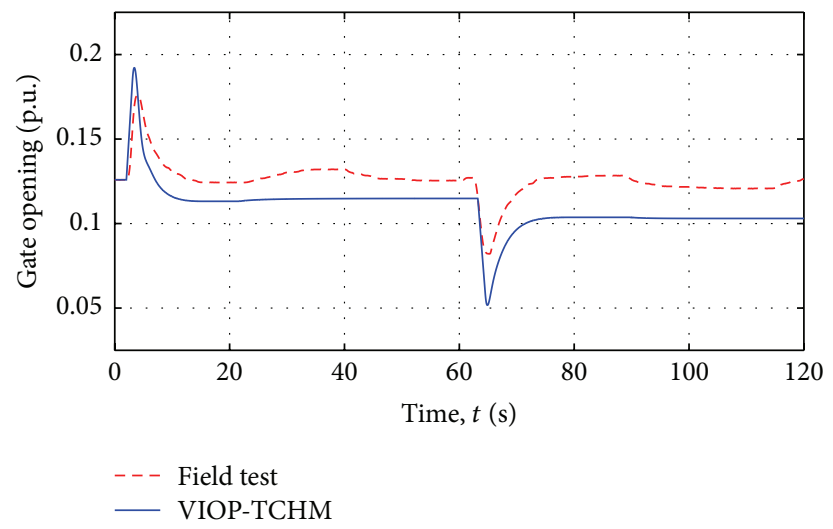

(c) Gate opening response

FIGURE 12: Response to $1 \mathrm{~Hz}$ no-load disturbance.

\section{Conflict of Interests}

The authors declare that there is no conflict of interests regarding the publication of this paper.

\section{Acknowledgments}

The authors acknowledge the financial support from the National Natural Science Foundation of China under Grant no. 51379160 and the National Technology Support Project of China under Grant no. 2013BAA02B01.

\section{References}

[1] Y. C. Cheng, J. B. Zhang, G. D. Chen, and D. H. Zhang, Hydro Turbine Governing System, China Water \& Power Press, Beijing, China, 1st edition, 2010 (Chinese).

[2] H. M. Chaudhry, Applied Hydraulic Transients, Springer, Berlin, Germany, 3rd edition, 2014.

[3] P. M. Anderson and A. A. Fouad, Power System Control and Stability, John Wiley \& Sons, New Jersey, NJ, USA, 2003.

[4] C. Q. Duan, "The correction iteration method and fast convergence program of error function for digital simulation of hydroturbine transient process," Chinese Science Bulletin, vol. 29, no. 22, pp. 1398-1402, 1984 (Chinese).
[5] K. L. Yang, "The characteristic-micro-increment simulation method for hydro-turbine transient process simulation," Journal of Hydraulic Engineering, no. 1, pp. 60-65, 1987 (Chinese).

[6] V. L. Streeter and E. B. Wylie, Fluid Transients, McGraw-Hill, New York, NY, USA, 1976.

[7] IEEE Working Group on Prime Mover and Energy Supply. Models for System Dynamic Performance Studies, "Hydraulic turbine and control models for system dynamic studies," IEEE Transactions on Power Systems, vol. 7, no. 1, pp. 167-179, 1992.

[8] P. Kunder, Power System Stability and Control, McGraw-Hill, New York, NY, USA, 1st edition, 1994.

[9] J. S. Chang, C. P. Bai, and M. H. Shou, "Dynamic characteristics of the load rejection of turbine unit in Tianshengqiao 2th Cascade Hydropower Station," Water Power, no. 7, pp. 35-38, 1995 (Chinese).

[10] Y. Z. Liu and J. S. Chang, "Numerical method based on internal character for load rejection transient calculation of a bulb turbine installation," Journal of China Agricultural University, vol. 13, pp. 89-93, 2008 (Chinese).

[11] J. Chang and J. S. Zhong, "Nonlinear simulation of the Francis turbine neural network model," in Proceedings of the International Conference on Machine Learning and Cybernetics, vol. 5, Shanghai, China, August 2004.

[12] W. D. Hong, H. G. Fan, and N. X. Chen, "Transient simulation coupling model of transient pipe flow and three-dimensional flow in turbine," Journal of Hydroelectric Engineering, vol. 32, no. 6, pp. 262-266, 2013. 
[13] H. Fang, L. Chen, N. Dlakavu, and Z. Shen, "Basic modeling and simulation tool for analysis of hydraulic transients in hydroelectric power plants," IEEE Transactions on Energy Conversion, vol. 23, no. 3, pp. 834-841, 2008.

[14] A. Riasi, M. Raisee, and A. Nourbakhsh, "Simulation of transient flow in hydroelectric power plants using unsteady friction," Journal of Mechanical Engineering, vol. 56, no. 6, pp. 377-384, 2010.

[15] J. L. Woodward, "Hydraulic-turbine transfer function for use in governing studies," Proceedings of the Institution of Electrical Engineers, vol. 115, no. 3, pp. 424-426, 1968.

[16] IEEE Committee Report, "Dynamic models for steam and hydro turbines in power system studies," IEEE Transactions on Power Apparatus \& Systems, vol. 6, pp. 1904-1915, 1973.

[17] G. I. Kravchenko, Transients in Hydroelectric Power Plants, China Water \& Power Press, Beijing, China, 1981 (in Chinese).

[18] IEEE Standards Association, IEEE Std 1207-2011: IEEE Guide for the Application of Turbine Governing Systems for Hydroelectric Generating Units, IEEE, New York, NY, USA, 1st edition, 2011.

[19] S. Timothy, Numerical Analysis, Posts \& Telecom Press, Beijing, China, 1st edition, 2010. 


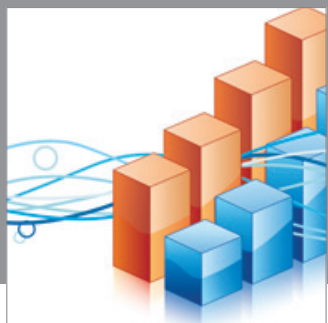

Advances in

Operations Research

mansans

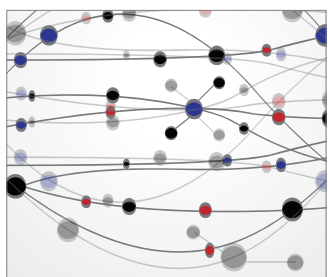

The Scientific World Journal
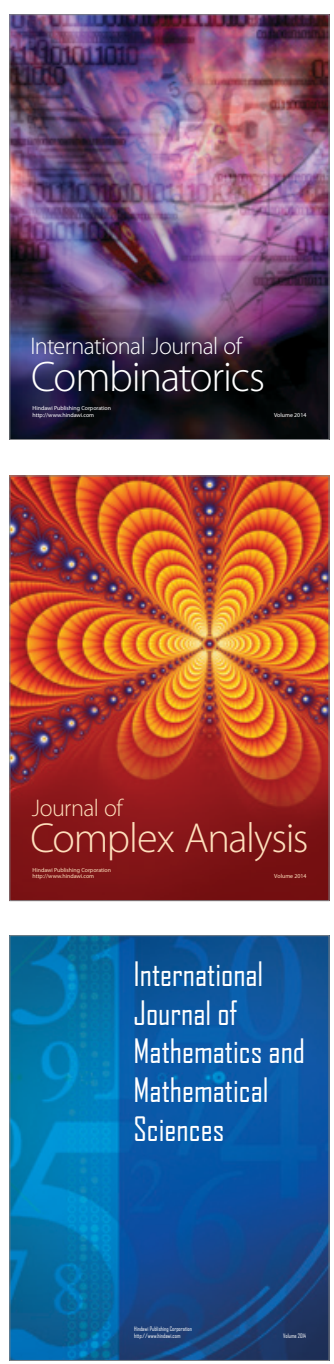
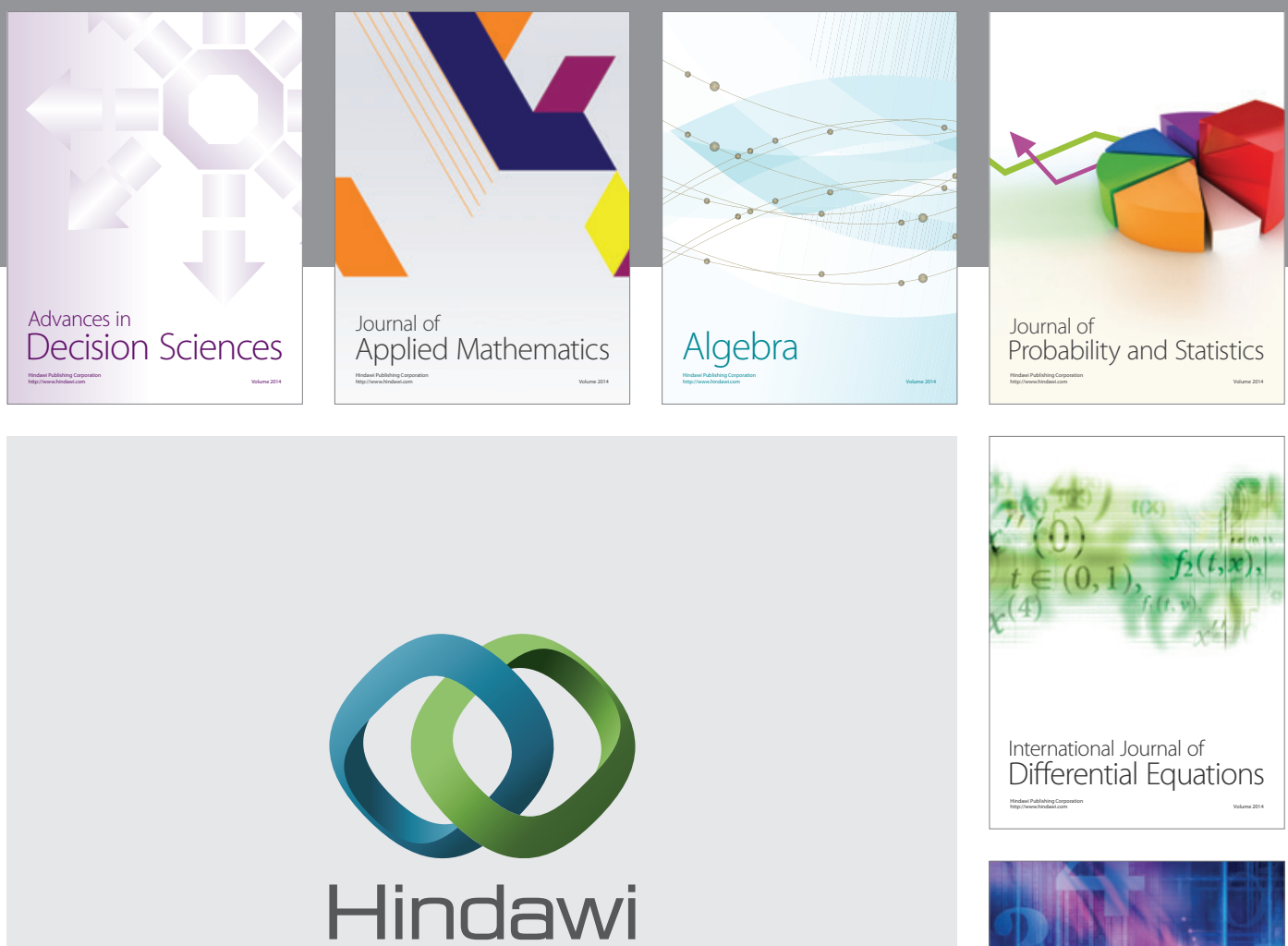

Submit your manuscripts at http://www.hindawi.com
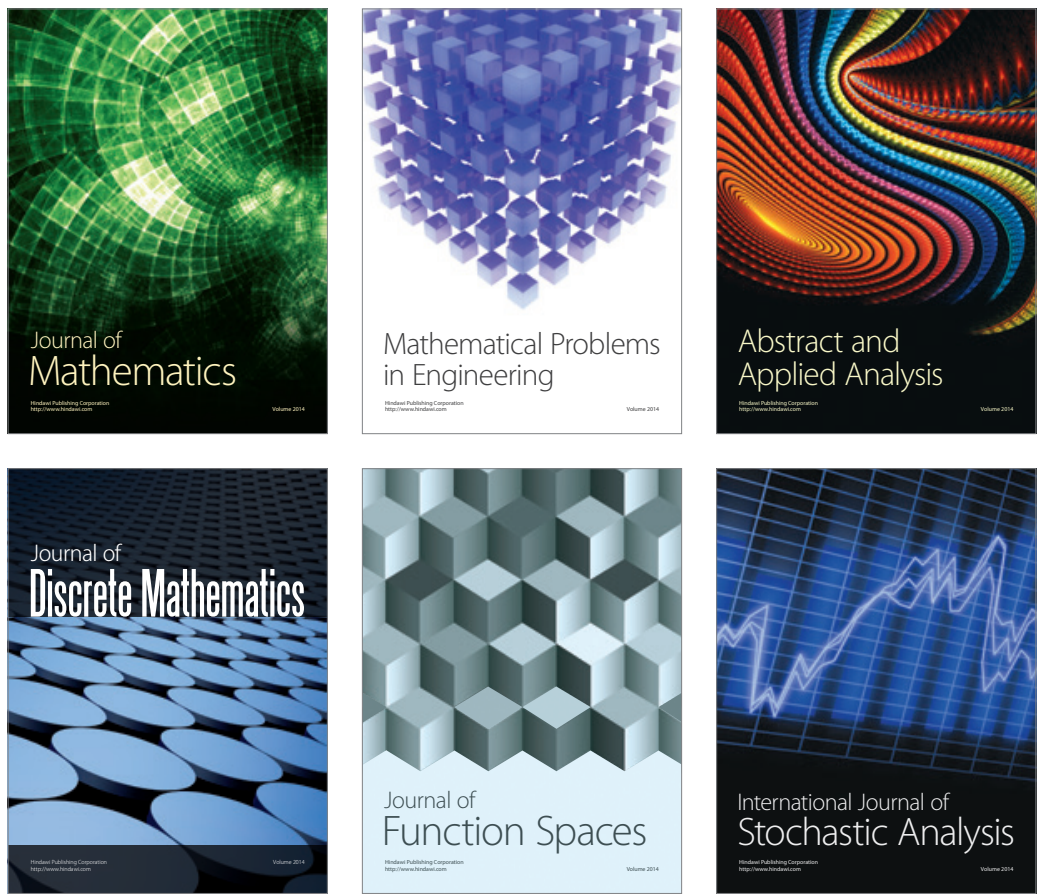

Journal of

Function Spaces

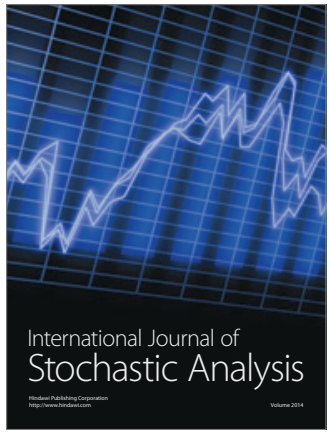

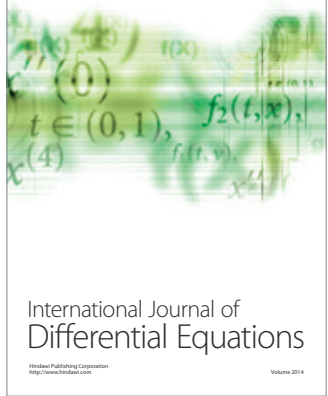
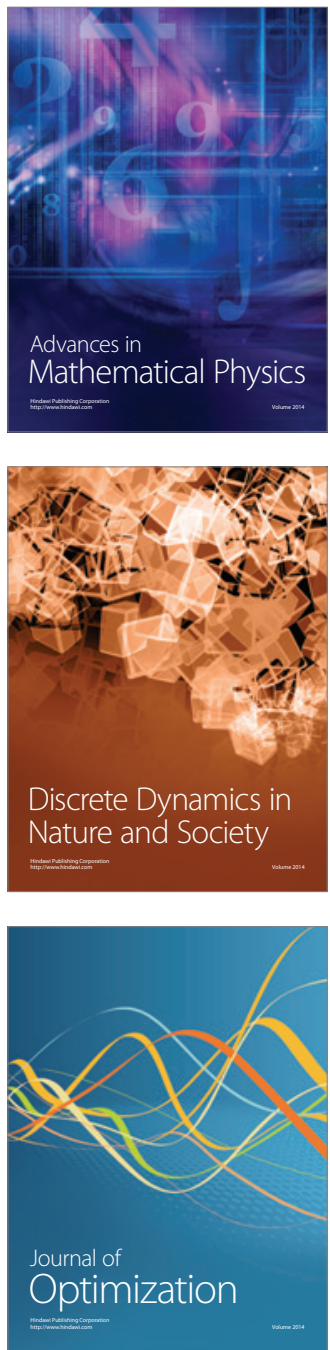